Journal of Black Studies 19: 411-21.

6. Most recently, Bishetta P. Merritt (1986), “Jesse Jackson and Television: Black Image Perception and Affect in the 1984 Democratic Campaign Debates," Journal of Black Studies 16: 347-67; and Steven A. Shul and Albert C. Ringelstein (1989), "Presidential Attention, Support, and Symbolism in Civil Rights, 1953-1984," The Social Science Journal 26: 45-54.

7. A slightly different variation of this model can be used for pre-determined constructs. A very nice discussion is Todd $M$. Davis and James E. McLean (1988), "Simplifying Ranking Tasks in Survey Research: A
Method and Example," Psychological Reports 62: 987-92.

8. Eric Woodrum (1984), " "Mainstreaming' Content Analysis in Social Science:

Methodological Advantages, Obstacles and

Solutions," Social Science Research 13: 1-19.

9. Content analysis is a useful way of drawing emotion from words. In her study, Susan B. Shimanoff [(1985) "Expressing Emotions in Words: Verbal Patterns of Interaction," Journal of Communication 35 (Summer): 16-31] demonstrates that the analysis of verbal contents for affect can produce statistically significant interrater reliability scores on fairly simple coding schedules.

\title{
The Individual Learning Contract
}

\author{
John F. Freie, Le Moyne College
}

... there are alternative ways to handle a classroom or a course ... . alternative assumptions and hypotheses upon which education can be built, alternative goals for which educators and students can strive. ...

\section{Carl Rogers}

Political scientists, often unconsciously, discourage transformational thought, not by what they teach but by the manner in which they organize their classrooms. This is done through using the traditional method of instruction, referred to by Freire (1970) as the banking concept of education. This approach treats students as empty vessels to be filled with knowledge. Courses are based upon that assumption-professors select the subject matter, and students dutifully complete the assigned readings; professors lecture, and students passively take notes; professors write exams, and students regurgitate the information fed them; professors discipline, and students are disciplined. This approach, dominant in higher education and political science, is inconsistent with the education of a democratic citizenry.

Alternatives are available.

The Independent Learning Contract (ILC) is a nondirective approach to teaching which moves in the direction of civic education for democracy while operating within the parameters of traditional education. As Rogers (1983) puts it, "contracts provide a sort of transitional experience between complete freedom to learn whatever is of interest and learning that is relatively free, but that is within the limits of some institutional demand or course requirement" (p. 140).

\section{Working together, the student and professor shape a program of study which is founded upon the student's compelling interests.}

\section{The Independent Learning Contract}

The Independent Learning Contract (ILC) is an approach built upon the evolving interests and aspirations of each student. Working together, the student and professor shape a program of study which is founded upon the student's compelling interests. I have used the ILC at every level of undergraduate political science education. With adaptation, it has been used by colleagues in the humanities and natural sciences in small colleges as well as at larger universities. Neither the level of instruc-

\section{About the Author}

John Nicolay is director of the M.P.A. program at Central Michigan University and an assistant professor in the department of political science. tion nor the discipline present major obstacles to its implementation.

\section{The Contracting Procedure}

Contracts are developed by negotiating with students. Analytically, negotiations occur in three areas: goals, activities, and evaluation criteria; practically, the entire process of developing a contract can usually be completed in two student-teacher meetings. On the first day of class the contracting procedure is explained, and the first student-teacher meetings are scheduled. The assignment given each student is to read material on the ILC (which is provided) and to prepare a written statement identifying individual goals to accomplish in the course.

Goals. Students are asked to identify semester goals in three areas: content, liberal arts skills, and life goals. Content interests relate to the formally designated subject matter of the course. Students are asked to skim the reading materials the professor has selected to get a general idea of what subjects will be covered. A minority of students develop detailed, specific content-related objectives; most include vague, general statements; some omit identifying goals in this category altogether. The professor needs to reassure students that it is acceptable not to have clearly defined goals at this point. For 
many students specific content goals emerge later in the semester after they have been exposed to the subject.

Virtually all students identify goals in the area of liberal arts skills. By separating skill development from content it becomes easier to expand the range of learning skills usually emphasized. Students most immediately think of liberal arts skills as focusing on analytical writing and oratory, but the skills may be expanded to include creative writing, poetry, organizational skills, discussion skills, reading comprehension, listening skills, group facilitation skills, and forms of artistic expression. Separation of skill development from content also makes it easier to identify and remedy learning difficulties. In student-teacher meetings with the agenda of the meetings focused on skill development, students who are experiencing particular difficulties jump at the opportunity to talk about those problems and are open to developing programs to correct them.

The third and final area of goalsetting relates to the personal life of the student. This is an area usually of critical importance to the student, but it is seldom considered a legitimate area of concern in the conventional classroom. By building this dimension into the course it is possible to directly link the subject matter with the everyday life of the student -to, in effect, make the course "relevant."

Activities. The second step in negotiating a contract involves identifying specific activities (an "activity package") the student will undertake to accomplish the identified goals. Students are encouraged to think creatively about ways to improve weaknesses and to build upon strengths. The activity package includes projects that will be graded as well as those that will be nongraded. Students determine the emphasis to be placed on each graded activity by assigning percentages. Nongraded activities provide a safety-net that gives students the opportunity to work in areas where they need improvement and to experiment with projects that involve risk because of the fear of failure.
The activity statement is a critical part of the contracting process because the activities structure the relationship of the student to the operation of the classroom. Some activities might involve groups of students; some might be done outside of the formal classroom setting; others might be done individually and shared with the class. To assist students in selecting activities, a list of projects that have been undertaken in previous years is provided.

Two things are important when negotiating the activity package. First, there must be a firm link

\section{A learning facilitator, on} the other hand, asks different questions, not of himself or herself, but of the students: "What problems do you want answers to? What do you want to learn? What questions do you never get answers to?"'

established between goals and activities. Second, clarity must be obtained about how and when activities will be completed, what specific products will be produced, if the activities will be shared with others, etc. The role of the professor is to point out potential problems, seek clarity, encourage experimentation, and reassure those who remain anxious.

Evaluation Criteria. The final area of negotiation occurs on evaluation criteria. Since there is considerable variety in activities, and since similar activities might be used to accomplish different purposes, the criteria used to evaluate the quality of student performance must be explicit. Identifying evaluation criteria initially falls within the realm of expertise of the professor. Although negotiations may occur in this area, the pattern commonly followed is for the teacher to suggest criteria and for the student to respond to those suggestions.
Finalization. The contract is complete when the goals, activities, and evaluation criteria are agreed upon and listed on a contract form (see Appendix for an example). This form is signed by both the professor and the student. The original is kept on file, and a copy is returned to the student. It is the student's responsibility to complete the activities listed on the contract.

The contracting procedure works best if it can be completed within the first three weeks of the semester, but this is dependent upon the number of students in the class and the complexity of their contracts. Contracts may be revised during the semester as objectives change, although it is often necessary to indicate a reasonable time beyond which changes will not be accepted.

\section{Classroom Atmosphere: Teacher Skills}

The ILC provides the necessary, but not sufficient, conditions for effective nondirective learning. As is true of most educational approaches, ultimate success depends on the teacher's ability to make it work. The skills and characteristics needed by the teacher in the ILC classroom are those associated with facilitation.

A nondirective teacher, a learning facilitator, starts from different assumptions than a conventional teacher, asks different questions of students, and creates a different classroom atmosphere. A conventional teacher may ask questions such as: "How can I plan a proper curriculum for a student? How can I teach in such a way as to motivate the student so that she or he will learn? How can I best create exam questions that will show how much the student has taken in?" A learning facilitator, on the other hand, asks different questions, not of himself or herself, but of the students: "What problems do you want answers to? What do you want to learn? What questions do you never get answers to?"' For the ILC to be effective the teacher must create an atmosphere open to the expression of needs and interests of the students. To do this, the teacher must project feelings of openness, acceptance, 
support, trust, empathy, and a feeling that what is going on is important.

\section{Biases of the ILC}

Teaching is not as simple as what is "good" or "bad." The concept of "good" when applied to teaching is more appropriately stated "good for what?" or "good for whom?" Any approach contains within it biases, and those biases create environments that encourage students to learn in particular ways.

The ILC has, within it, biases that cut sharply and dramatically to emphasize some features of the learning process and deemphasize others. Following are some of the biases that are seen as educationally beneficial.

1. Diversity. Because the ILC starts from student interests, the range of perceptions that emerge in a course is automatically expanded. Students not only identify unique objectives, but they differ in how to accomplish them. The consequent diversity enlivens the classroom, adds intensity to student involvement, and makes the class more interesting.

Many professors (even traditional ones) are interested in creating a classroom atmosphere that encourages the articulation of multiple viewpoints. An advantage of the ILC is that it not only assures that multiple perspectives will emerge but that they will originate from the interests of the students. They are not seen by students as artificial because they are not superimposed. Consequently, they are considered in a more serious manner.

2. Interaction. Another advantage of the ILC that is encouraged is student interaction. For teachers wishing to encourage student interaction and to develop a sense of community, shared activities may be required. This may be done by asking all students to include an activity that requires cooperation of all in the class (e.g., a student-organized trip).

The ILC also reorients studentteacher interaction away from conflict and toward cooperation-in the classroom, in negotiation meetings, and on supervised activities. Such a variety of interactions makes it more likely that students and teachers will view each other holistically.

3. Responsibility. The ILC shifts the burden of responsibility for making the class a worthwhile learning experience from the professor to the student. Contracts also encourage responsibility by being open and honest about course requirements, grading criteria, and the structure of the class itself. Students must take individual responsibility for fulfilling their contracts, while the professor coordinates and schedules the activities, attempting to weave them into a coherent class dialogue.

But the professor is also a part of the learning process. It is important to indicate to students what external pressures impinge on the teacher's time (e.g., grade deadlines, etc.). The

\section{Politics is practiced in the classroom; it is not merely something to be studied.}

nondirective professor does not merely give the class over to the students; she/he is also a part of the class and, as such, has needs, interests, and obligations that must be recognized. The ILC makes it easier for both the professor as well as the students to openly acknowledge those concerns.

Obviously, not all students fulfill their contractual obligations. In such instances appropriate consequences must occur, but they should not be considered "punishments." The consequences of not turning material in by appropriate deadlines or not completing activities need to be agreed upon during the initial contracting process. Accepting the consequences of (in)action is part of being a responsible person.

4. Skill development. Because the ILC is tailored to the needs of the individual student it is a particularly effective approach to improving liberal arts skills. The ILC does not assume that there is a single, or even a best, way of learning. Mastery of any skill may be accomplished in numerous ways, and it is up to the student working in concert with the teacher to determine which approach is most appropriate. In doing so, the student must develop self-under- standing and self-awareness to accurately assess personal strengths, weaknesses, and learning style.

The ILC makes it easier to pinpoint specific weaknesses, and reduces the anxiety commonly associated with correcting deficiencies. Most student anxieties center around grades. The ILC encourages work on weaknesses by, first, providing an opportunity for students to express their feelings in a nonthreatening atmosphere and, second, by allowing them to remove the external cause of anxiety, the grade. If grades are identified as a blockage to learning, those activities may be listed as nongraded.

5. Practicing politics. Professional political science regards politics as important, but as an activity external to the classroom. Mainstream political science defines politics in conventional terms and relegates the political scientist to the role of dispassionate observer (i.e., "scientist"). Likewise, the professional political science professor remains detached from the political world. In teaching, the traditional political science professor declines to play the role of citizen and, by doing so, implicitly passes on the norms associated with passivity.

The ILC, because it goes beyond conventional subject matter to challenge the underlying constitution of the course itself, explicitly deals with political concerns. By challenging conventional ways of structuring a course, it legitimizes previously unacknowledged interests and gives them the opportunity to be publicly displayed. Politics is practiced in the classroom; it is not merely something to be studied.

While the ILC does not move as far in the direction of liberating students as some might like, it does alter the authority relationships usually found in the classroom. Rather than having a rigid hierarchy, authority is shared between the student and the professor and the nature of that sharing is variable, dynamic, and complex. It moves the class away from commonly accepted "power-over" relationships toward "power-with" relationships. This, of course, creates opportunities as well as problems. At the very least, however, it provides effective defense for the criticism, "how can you teach 
about the importance of democracy and then be a dictator in class?"'

\section{Criticisms}

Every approach to learning carries with it a host of problems. Because the ILC challenges the basic assumptions of conventional courses it is often met with hostility on the part of students, faculty, and administrators. Following are some of the more frequently raised concerns.

1. Contract teaching deemphasizes content and rigor. This criticism charges that the ILC lets students study "whatever they want" and that what they choose to learn may have nothing to do with the topic of the course. What's more, lazy students get away with doing very little.

At least part of this criticism is based upon a false separation of process and content. While it is true that the ILC is concerned mainly with the process of learning, the cognitive dimension is nonetheless present; it is embedded within the contracts themselves because it is what is negotiated. Where the ILC differs from conventional approaches is that it places the subject matter within the context of student interests and needs. In reality, all courses, conventional as well as experimental, contain within them deviation from the predetermined subject matter. The ILC recognizes that deviation and provides the professor with an opportunity to make conscious decisions about it. If professors are concerned about deviation, they may require that readings be completed by all students or that graded activities must be related to the subject of the course. For those less concerned with deviation, students may be given greater freedom to select topics and activities.

2. Fear of chaos. The ILC alters authority relationships. Students will lose respect for authority; chaos will result.

It is certainly an intention of the ILC to challenge our predetermined assumptions about authority in the classroom. In democratic systems there is an uneasy tension between expertise and rights, and authority remains a poorly defined concept. Although providing no definitive answers, the ILC highlights the ten- sion inherent within democratic systems.

The risk that chaos will break out is not as great as one might at first imagine. By the time students reach college they have had years of training. What "wildness" and urges to experiment they may have had have largely disappeared. Given freedom, their initial response is to either do nothing or to seek their own repression. The role of the professor is not to control behavior but to encourage experimentation. Furthermore, people who are committed to a goal require little external discipline. An objective of the ILC is to encourage self-discipline by giving students the freedom to work on things of interest to them in their own fashion.

3. Students won't work hard. One of the most common concerns expressed about the ILC is that students, given the freedom to decide what they will do, will do very little. Students, it is contended, are motivated by grades and, consequently, they will do as little as possible to get by.

To be sure, some students will use the contract as a way of avoiding work. Abuse does occur. But there is every reason to believe that the same sort of abuses occur in conventional learning environments. Just because professors assign readings does not mean that they will actually be read. Cursory observation leads me to conclude that students using the ILC select and complete about the same amount of work as students in traditional courses. This should not be surprising. Students have not only been conditioned to expect a certain amount of work in class, but they are motivated by the same fears of risking too much of the grade on too few activities just as professors in traditional classes are when they require a variety of exams and papers.

\section{Conclusion}

Political scientists are presented with a unique challenge: How do we study politics and, at the same time, train students to function effectively as democratic citizens? Nondirective approaches to education, such as the Individual Learning Contract, offer one answer. Through the use of the ILC students engage in dialogue on the subject matter of the course and begin to see the transformational possibilities of education by building upon their own needs and interests. When students are involved in structuring the classroom, they learn valuable lessons about acting responsibly within a communal context and feel the liberating effects of education in their own lives.

\section{Appendix}

Following is a contract form used in an Urban Politics course:

\section{LEARNING CONTRACT Urban Politics PSC 322}

I __, the undersigned (party of the first part), agree to the following conditions with respect to my involvement in the course Urban Politics (PSC 322). As such, this constitutes my contract which identifies the requirements for the course with the professor (party of the second part) and my colleagues (unsigned parties of the third part).

(1) I will attend regularly and participate actively in class activities (e.g., discussions, presentations, trips, etc.). If I am absent from regularly scheduled class activities it may be assumed that I am absent for "good cause." I consider the following reasons "good cause" for absence:

(2) I will attempt to achieve the following GOALS in the class (this is my Goal Statement):

(3) The activities I am contracting to perform in this class are listed at the end of this contract (Activity Statement). Some activities will be assigned grades to be used to determine the final course grade; some will not be assigned grades. (See attached.)

(4) The Evaluation Criteria which will be applied to those activities in order to arrive at "grades" are also included in the Activity Statement.

(5) This contract is subject to revision and/or modification any time prior to three weeks before the conclusion of the semester (April 11th). Revisions after that date must be in "good faith" and are allowed only under unusual circumstances.

(6) Failure to fully implement any or all parts of this contract may result in receiving a grade of " $F$ " for those 
uncompleted sections and/or withholding of the final grade.

(7) Implementation of the contract is the responsibility of the party of the first part (the student).

(party of the first part)

student signature

(party of the second part)

professor signature

(unsigned party of the third part)

(date)
[Activities, along with evaluation criteria, are listed here.]

Note

1. For a more detailed description of how the ILC may be implemented in classes contact the author.

\section{References}

Freire, Paulo. 1970. Pedagogy of the Oppressed. New York: Continuum. Rogers, Carl K. 1969. Freedom to Learn. Columbus, $\mathrm{OH}$ : Charles E. Merrill.
About the Author

John F. Freie

John F. Freie is associate professor and chair of the department of political science at LeMoyne College. He is former chair of the board of directors of Educators for Social Responsibility. His major area of study is electoral behavior.

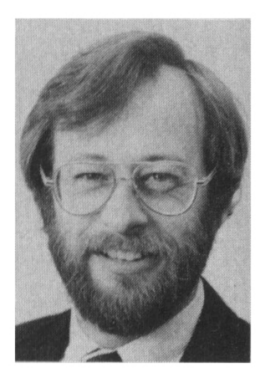

\title{
The Dilemma of Teaching Political Science Research Methods: How Much Computers? How Much Statistics? How Much Methods?
}

\author{
Pamela H. Rodgers, University of Wisconsin-La Crosse \\ Cecilia Manrique, University of Wisconsin-La Crosse
}

One of the goals of many higher education institutions with political science programs has been to incorporate quantitative political analysis in the curriculum as a result of the focus on quantification and empirical research methods in the discipline. Professors and students in political science have had to struggle with the dilemma of determining how much quantification and computer instruction should take place. One of the issues involved was what portion of research methods courses should be devoted to quantification. Teachers had to teach, and students had to learn, statistics in addition to subject matter.

Today, the dilemma is even greater with the advent of computing.

Teachers and students face a threefold problem: how much content, how much statistics, and how much computing to teach and learn to make such a course worthwhile for both constituents.

\section{How Much Computers?}

In a world of growing technological knowledge, students in the social sciences are being forced into the computer world with the increased use of word processing, data bases, and on-line electronic media. Political science has seen more opportunities for students to analyze raw data in the areas of American Government and Comparative and International Politics. Despite this, how much knowledge can a faculty member assume of the student? The teacher who decides to incorporate computers and statistical packages in a research methods course will have to recognize different levels at which students will come into the course.

There will be those who already have a strong computer background. Students now coming into college have had a greater experience with computers from grade school and high school as well as from parental guidance (Manrique 1990).

Some students will have a minimal computer background obtained from high school or introductory college computer literacy requirements. This preliminary knowledge will need to be supplemented to guide them through the use of statistical packages because most computer literacy courses ignore the teaching of basic statistical tools. Courses at the introductory level are traditionally geared towards background (what a computer is, what it does, how it works), computing history, and business applications in word processing, spreadsheets, and data bases.

A third group of students would have had no computer background at all. The research methods faculty cannot assume that students will have the necessary background for tackling the course work. A good teaching strategy would be to allow the more skilled students to mentor their 